\title{
Patients with underuse or overuse of inhaled corticosteroids have different perceptions and beliefs regarding COPD and inhaled medication
}

This article was published in the following Dove Press journal:

Patient Preference and Adherence

\author{
Kirsten Koehorst-ter \\ Huurne' \\ Marjolein Brusse-Keizer ${ }^{2}$ \\ Paul van der Valk' \\ Kris Movig ${ }^{3}$ \\ Job van der Palen ${ }^{2,4}$ \\ Christina Bode ${ }^{5}$ \\ 'Department of Pulmonary Medicine, \\ Medisch Spectrum Twente, Enschede, \\ the Netherlands; ' ${ }^{2}$ Department of \\ Epidemiology, Medisch Spectrum \\ Twente, Enschede, the Netherlands; \\ ${ }^{3}$ Department of Clinical Pharmacy, \\ Medisch Spectrum Twente, Enschede, \\ the Netherlands; ${ }^{4}$ Department of \\ Research Methodology, Measurement, \\ and Data Analysis, University of \\ Twente, Enschede, the Netherlands; \\ ${ }^{5}$ Department of Psychology, Health \\ and Technology, University of Twente, \\ Enschede, the Netherlands
}

Background: Therapy adherence in COPD is crucial for treating symptoms, preventing exacerbations, and related complications. To achieve optimal adherence, it is important to recognize and understand a nonadherent patient.

Objective: To study perceptions and beliefs regarding COPD and inhaled medication in COPD patients with poor adherence.

Methods: Twenty patients (10 underuse, 10 overuse) were interviewed in semistructured in-depth interviews, about mental and physical health, illness perceptions, knowledge regarding COPD, and experience with, knowledge of, and acceptance of COPD medication and inhalation devices.

Results: A majority of patients did not fully accept their disease, showed little disease knowledge, and many revealed signs of depressive mood and severe fatigue. Overusers reported more grief about decreased participation in daily life and were more frustrated in general. Underusers claimed using less medication because they felt well, did not want to use too much medication, and used their inhalation devices too long. Overusers reported medication "dependency"; they tended to catastrophize when being without medication and discarded inhalation devices too early because they feared running out of medication.

Conclusion: Overusers and underusers showed a different pattern in perceptions and beliefs regarding inhaled medication and COPD.

Practical implications: It is important to understand the reasons for under- and overuse. Is it related to practical issues regarding knowledge or is it influenced by beliefs and/or anxiety concerning COPD or medication? These issues need to be addressed for improving adherence.

Keywords: COPD, adherence, illness perceptions, medication beliefs, in-depth interviews

\section{Introduction}

In the treatment of COPD, therapy adherence is crucial not only for dealing with symptoms but also for preventing exacerbations and related complications. Adherence to inhaled corticosteroids (ICS) has, for example, been shown to be associated with reduced risk of death and hospitalization. ${ }^{1}$ In order to achieve optimal adherence in COPD patients, it is important to recognize and understand a nonadherent patient. This understanding can be used to guide patients and carers with respect to reaching an agreement with regard to therapy adherence. Nonadherence can present itself in different forms. After collecting medication the patient can underuse, overuse, or show improper use of the medication. ${ }^{2-4}$ Many adherence studies focus on nonadherence registered as underuse. However, overuse is an important form of nonadherence as well and can be related to different factors.
Correspondence: Kirsten Koehorst-ter Huurne

Department of Pulmonary Medicine, Medisch Spectrum Twente, PO Box 50000, 7500 KA Enschede, the Netherlands

Tel +3I 534872643

Fax +3I 534872676

Email kirstenterhuurne@gmail.com 
Therapy adherence in COPD patients is a multifactorial problem. One has to take into account medication, regimen, and patient factors. Adherence to inhaled medication in COPD is related to the type of inhaled medication and the device with which the medication is inhaled. ${ }^{5,6}$ Differences in adherence could be explained, at least partially, by feedback of inhalation, frequency of dosage, and the design of the device. ${ }^{6}$ Next to these medication factors, known patient factors that affect adherence are higher age, comorbid conditions, polypharmacy, cognitive decline, physical problems as hand-eye coordination, and problems with reading small print instructions. ${ }^{3}$ In the Cohort of Mortality and Inflammation in COPD (COMIC) cohort study, we already showed that a predictor for underuse of ICS was a higher forced expiratory volume in 1 second, while predictors for overuse were a lower forced expiratory volume in 1 second, more anxiety for dyspnea as scored with the Clinical COPD Questionnaire (CCQ), and current smoking, ${ }^{7}$ so it seems that under- and overusers have different characteristics.

To get more insight in the influence of patient factors on adherence, Leventhal proposed a Self-Regulatory Model. ${ }^{8}$ This model provides a framework for understanding adherence and nonadherence to treatment recommendations ${ }^{9}$ and is based on patients' beliefs of their illness in relation to treatment adherence. ${ }^{8}$ The model asserts that illness beliefs can be divided into 5 dimensions: illness identity, timeline, cause, consequences, and control-cure. ${ }^{10}$ In addition to illness beliefs, Horne et al ${ }^{9}$ showed for 4 chronic illness groups (asthma, renal, cardiac, and oncology) that beliefs about medication were related to reported adherence. Higher medication necessity scores correlated with higher adherence while higher concerns about the risk of dependence or long-term effects correlated with lower adherence. ${ }^{9}$ Therefore, Horne et al ${ }^{11}$ designed an extended selfregulatory model of treatment adherence which incorporates beliefs about treatment as well as illness perceptions. This model showed that in asthma patients concerns about potential adverse effects and more negatively perceived consequences of illness were correlated with lower adherence. ${ }^{11}$

In COPD, disease and medication perception has not been described in much detail. Which beliefs, experiences, or fears influence the use of inhaled medication? Although asthma and COPD are both obstructive diseases, asthma shows an intermittent process whereas COPD is a continuous process. We therefore believe that COPD patients might have different beliefs and perceptions with regard to their illness and their medication.

Therefore, we aimed to investigate the beliefs and perceptions about 1) COPD and 2) the inhalation treatment in COPD patients' nonadherent to ICS.
Using in-depth interviews, this study focuses on which components of the patients' perceptions and beliefs (based on the extended self-regulatory model of Horne et $\mathrm{a}^{9,11}$ ) and practical issues specific for inhaled medication can explain nonadherence to these inhaled medications.

Instead of defining nonadherence only as underuse, we also studied factors related to overuse of ICS. Furthermore, we compared the perceptions of patients with underuse and overuse to see if these perceptions differ. Studying patients' perceptions of both under- and overusers and comparing their perceptions is innovative in this field of research.

\section{Methods}

\section{Settings and study population}

This study is part of the COMIC study, a single-center prospective cohort study in Medisch Spectrum Twente Hospital, Enschede, the Netherlands. From December 2005 till April 2010, 795 COPD patients were included with a follow-up period of 3 years. The study was approved by the Medical Ethics Committee Twente (P05-49). All patients provided written informed consent, including consent for collecting all pharmacy records during the study period. To complement the current data with in-depth interview data, this new part of the study was judged as not being subject to the Medical Research Involving Human Subjects Act by the Medical Ethics Committee Twente (K15 08). The study was conducted according to the principles of the Declaration of Helsinki. For more detailed information, we refer to previous publications. ${ }^{5,12}$

\section{Therapy adherence}

Therapy adherence with ICS was recorded from patients' pharmacy records. The patients were not aware that their medication records were used for the monitoring of therapy adherence. Theoretical duration of exposure was calculated using information on dispensing date, total supply, and dosage regimen. This was expressed as a percentage and adherence was deemed good if it was $\geq 75 \%-\leq 125 \%$, suboptimal between $\geq 50 \%$ and $<75 \%$, and poor below $<50 \%$ (underuse) or above $>125 \%$ (overuse).

\section{Patient selection}

In order to study nonadherence, 10 patients who underused and 10 patients who overused their ICS were selected from the COMIC cohort and were invited for an in-depth interview. All patients provided written informed consent. Because the collection of the COMIC data ended in 2014, patients last enrolled in the cohort and still alive were consecutively contacted first; no further selection criteria where used. 


\section{Qualitative study design}

The interviews were conducted by 2 intensively trained psychology students at the patients' home or at the hospital. The interviews were semistructured using an interview guide with a structure based on the extended self-regulatory model of Horne et al, ${ }^{9,11}$ supplemented with "Treatment factors" like experience with and acceptance of COPD medication and inhalation device, next to knowledge of the used medication and inhalation device. Self-management information and demographic data concluded the interviews (Supplementary material A).

Each student interviewed 5 participants with registered underuse for ICS and 5 with overuse, while blinded for the adherence pattern of the patient. Patients were sampled until a sufficient number to provide topic saturation (no additional topics emerged during the final phase of analysis) was reached. ${ }^{13}$

\section{Data analysis}

The interviews were transcribed verbatim, and data were imported in ATLAS.ti version 7.5.15 (Scientific Software Development GmbH, Berlin, Germany). Our approach was initially deductive, based on the abovementioned 5 dimensions of the extended Self-Regulatory Model used by Horne et al, ${ }^{9,11}$ illness identity, timeline, cause, consequences, and controlcure, followed by an inductive phase to reach saturation of analysis. Separate categories regarding specific medication issues in COPD patients were identified and coded, including knowledge and experience with medication and inhalation devices (for a schematic overview see Figure 1). During the coding process, the authors were blinded for the patients' under- or overuse. Initially the first author coded 4 interviews using a concept coding scheme, which was adjusted by discussion in the research team. The coding scheme is given in supplementary material B. The second author coded 4 interviews to establish consensus ( $80 \%$ or more was regarded as sufficient). Answers of patients with under- and overuse were grouped for each code to check for different patterns. The first 2 authors screened the grouped quotations independently for meaningful differences between the 2 groups. Striking differences in frequencies and/or content of answers were discussed in the research team for consensus.

The results of the interviews are described per dimension of the model (Figure 1). The numbers at the end of the quotations correspond with the patient number.

\section{Results}

The interviewed underusers were more often male, slightly younger, and had a better lung function and felt more
1. Illness identity
$\rightarrow$ Disease (description)
$\rightarrow$ Complaints/disease symptoms
2. Illness timeline
$\rightarrow$ Curability
$\rightarrow$ Course of the disease over time
$\rightarrow$ Future development/hope
3. Illness consequences

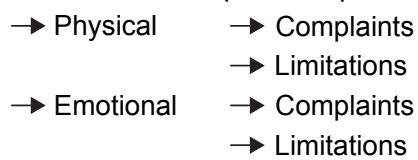
4. Illness cause
5. Illness cure/control
$\rightarrow$ Coping $\quad \rightarrow$ Psychological
$\rightarrow$ Practical
6. Treatment necessity
7. Treatment concerns
$\rightarrow$ Acceptance/nonacceptance
$\rightarrow$ Memory, influence on adherence
$\rightarrow$ Side effects
$\rightarrow$ Dependency
8. Inhaled medication use $\rightarrow$ Knowledge inhaled medication
$\rightarrow$ Experience with inhaled medication
$\rightarrow$ Daily routine
9. Inhalation devices
$\rightarrow$ Knowledge of device
$\rightarrow$ Experience with device

Figure I Self-Regulatory Model extended with specific COPD treatment topics.

restricted by their dyspnea (higher modified Medical Research Council score) compared to overusers. Smoking status was the same for under- and overuse. In both groups, 1 patient had had a severe exacerbation with hospital admission prior to inclusion (Table 1). Patients were treated according to the Global Initiative for Chronic Obstructive Lung Disease (GOLD) guidelines applicable during the time of follow-up of the COMIC cohort.

Table I Baseline characteristics

\begin{tabular}{|c|c|c|}
\hline Baseline characteristics & $\begin{array}{l}\text { Underuse } \\
(\mathrm{n}=10)\end{array}$ & $\begin{array}{l}\text { Overuse } \\
(n=10)\end{array}$ \\
\hline Age (median, IQR) & $58.8(45-75)$ & $62.0(54-74)$ \\
\hline Sex, number of males (\%) & 7 (70.0\%) & $3(30 \%)$ \\
\hline \multicolumn{3}{|l|}{ Smoking status, N (\%) } \\
\hline Current smoker & $3(30 \%)$ & $3(30 \%)$ \\
\hline Ex-smoker & $7(70 \%)$ & $7(70 \%)$ \\
\hline \multicolumn{3}{|l|}{ Lung function, mean (SD) } \\
\hline $\mathrm{FEV}_{\text {, in liters }}$ & $1.6(0.5)$ & $\mathrm{I} .3(0.4)$ \\
\hline $\mathrm{FEV}_{1} \%$ predicted & $49.4(9.5)$ & $53.8(18.8)$ \\
\hline $\mathrm{FEV}_{1} / \mathrm{VC}$ ratio & $46.7(13.0)$ & $41.5(11.7)$ \\
\hline mMRC score, mean (SD) & I.3 (0.8) & $\mathrm{I} .0(\mathrm{I} .2)$ \\
\hline $\begin{array}{l}\text { Patients with I severe } \\
\text { exacerbation prior to inclusion }\end{array}$ & I (I0\%) & I (10\%) \\
\hline \multicolumn{3}{|l|}{ COPD stage, N (\%) } \\
\hline GOLD I & $0(0 \%)$ & $\mathrm{I}(10 \%)$ \\
\hline GOLD II & $4(40 \%)$ & $4(40 \%)$ \\
\hline GOLD III & $6(60 \%)$ & $4(40 \%)$ \\
\hline GOLD IV & $0(0 \%)$ & $\mathrm{I}(10 \%)$ \\
\hline
\end{tabular}

Abbreviations: $\mathrm{FEV}_{1}$, forced expiratory volume in I second; mMRC, modified Medical Research Council; GOLD, Global Initiative for Chronic Obstructive Lung Disease; IQR, interquartile range. 


\section{Illness identity}

The first dimension of the Self-Regulatory Model is illness identity, how a person views his illness. Most patients could not give a clear definition of COPD. The descriptions vary from emphysema to airway obstruction. The symptom most often described as typical for COPD was dyspnea (Table S1). The interview data showed no distinct difference between under- and overusers.

\section{Illness timeline}

The factor timeline represents how the patient believes the illness will develop over time. Most patients (14) believed COPD cannot be cured. The most optimistic expectation was that the situation stays stable as long as possible (Table S1). There was no visible difference between under- and overusers in beliefs about curability. However, a difference between over- and underusers was a hope for improvement expressed by 4 patients with overuse versus none of the patients with underuse.

Most patients perceived their condition as stable (Table S1). The few patients who experienced improvement in their symptoms had quit smoking or had made a drastic change in lifestyle (e.g. weight loss).

Worrying about the future was similarly distributed between under- and overusers. Half of the patients worried about the future ( 5 under-, 5 overuse).

\section{Illness consequences}

This component comprises patients' beliefs about the severity of their illness and its impact on physical, social, and psychological functioning.

Physical problems mentioned most were dyspnea, shortness of breath, fatigue, and cough. These symptoms influenced the everyday activities in COPD patients. Patients experienced problems with walking (long) distances, and walking stairs was mentioned several times as being extremely difficult (Table S1).

There was no difference between under- and overusers in described symptoms or problems with everyday activities.

Most patients (under- and overusers) experienced limitations in their daily life activities. They could do all the things they used to do. Overusers were more explicit in their grief about being limited in participating in daily life. More patients with overuse reported irritable mood (2 under-, 5 overuse).

Some patients experienced anxiety or fear of dyspnea (3 under-, 2 overuse).
Half of the interviewed patients ( 4 under-, 6 overuse) experienced a depressive mood; other patients reported no signs of a depressive mood.

\section{Illness cause}

For the cause of COPD, the majority of patients mentioned smoking as a possible cause ( 8 underuse, 8 overuse) next to a hereditary component or a genetic predisposition for lung disease (4 underuse, 6 overuse) and environmental factors like pollution (Table S1). Differences between under- and overusers were not detected.

\section{Illness control/cure}

These are the patients' beliefs about the amenability to control or cure their illness. This component contains quotations on acceptance of the disease and coping with COPD by adapting behavior and using tools to improve daily life.

Only 4 patients described clearly that they accept their COPD ( 3 under-, 1 overuse). Seven patients reported accepting their disease, but only since they feel that they have no other choice ( 4 under-, 3 overuse). And 8 patients could not accept their disease ( 3 under-, 5 overuse). Overall, patients with overuse were less able to accept their disease (Table S1).

Most patients used tools and devices to support their daily life activities; for example riding an e-bike. Then, patients paced activities in order to participate in daily life (Table S1). There were no differences between under- and overusers.

Many patients had social support in their close network, help from a partner, family, or friends, for example, partners or guests smoking outside the house because they do not want to burden the patient. When needed, the pharmacy offered support by delivering medication at home (Table S1).

\section{Necessity of pharmacological treatment}

This component shows the quotations of the patients concerning beliefs about the necessity of the medication and attitude of the patients toward the medication. None of the patients completely accepted their inhalation treatment. Underusers claimed using less medication because they felt well or because they did not want to use too much medication. Overusers reported using medication took too much time, being forced to think of the use of medication all day long, and its effect on daily life activities (Table S1).

Some patients experienced memory problems. Most of them claimed this did not affect their medication use. The patients that acknowledged they sometimes forgot to use their medication were mostly underusers. Overusers claimed 
they did not forget, because they needed the medication (Table S1).

\section{Treatment concerns}

The next quotations show the possible concerns for adverse effects and the side effects patients experienced. Some patients reported that they experienced side effects, and in a few cases they received substitution medication to overcome this. Mentioned side effects were hoarseness, irritation of the throat, and coughing (Table S1). Differences in side effects between under- and overusers were not detected. Underusers believed they needed the inhaled medication in order to experience less symptoms. In contrast, overusers reported medication "dependency" in the sense that they tend to catastrophize when being without medication, eg, patients reported they do not go anywhere without their medication, they feel safe when carrying their medication, and some claimed that they panic when they forgot to take the medication with them (Table S1).

\section{Inhaled medication use}

This component contains the results concerning knowledge of the effect of and experiences with the use of inhaled medication. The knowledge regarding the inhaled medication was diverse. Most patients were able to describe the expected effects of medication, for example anti-inflammatory or for relieving dyspnea. However, some patients were not able to describe which effect belonged to which medication. Especially, overusers reported wrong knowledge of their medication, for example, saying medication was anti-inflammatory while it was a short acting $\beta$-agonist, or thinking a medication was short acting (had to be taken every few hours), while it was long acting and had to be used once or twice a day (Table S1).

A striking result was the perception of several patients (4 under-, 2 overuse) that the medication was not able to prevent exacerbations or to slow down disease progression, which is the main reason for prescribing ICS in COPD (Table S1).

Although the knowledge of the used inhaled medications is diverse and sometimes incorrect, all patients experienced positive effects of the medication.

Most patients claimed that they used their medication in a daily routine ( 9 under-, 8 overuse). Two patients with overuse described they did not have fixed times at which they took their medication (Table S1).

\section{Inhalation devices}

The knowledge about functioning/handling of the inhalation devices was low. Especially, knowledge on how to determine that a device was empty was stated incorrectly by many patients. Patients with registered overuse seemed to discard their inhaler too early just to be sure they inhaled medication (Table S1).

With a Metered Dose Inhaler (MDI) a patient can still actuate with little or no drug beyond the maximum number of dosages left in the canister. Patients with registered underuse answered they used their MDI until it stopped, which is using the inhaler too long after it has released its last dosage.

Patients using devices with a dose counter knew when their device was empty. Then, there were patients that were able to use devices without a dose counter by using a note on the calendar reminding them when to discard the device (Table S1).

In contrast with the lack of knowledge on the function of the device, patients' experience on the use of the device was overall stated as easy. Some patients had negative experiences with a specific device, for example not having enough inspiratory flow to inhale the medication. One patient claimed he did not like the spacer. Also, a patient with overuse claimed an MDI did not release the dosage as wanted (Table S1).

\section{Discussion and conclusion Discussion}

The aim of this study was to investigate the beliefs and perceptions about 1) COPD and 2) the inhalation treatment in COPD patients nonadherent to ICS.

Our main findings with regard to beliefs and perceptions about COPD were that many patients did not accept their disease, showed little knowledge regarding their disease, and many showed signs of depression and fatigue. Overusers reported more grief about losing participation in daily life and were irritable more often. The main findings for beliefs and perceptions about the inhalation treatment were that underusers claimed using less medication because they felt well, did not want to use too much medication, and used their inhalation devices too long after they were empty. Overusers reported medication "dependency" in the sense that they tend to catastrophize when being without medication and discarded inhalation devices too early because they feared running out of medication.

These differences and the abovementioned practical issues provide possible explanations for the registered under- and overuse.

The majority of the nonadherent patients were not able to accept their disease and the accompanied treatment. This finding is in line with Menckeberg et $\mathrm{al}^{14}$ who showed a 
relation between ICS user attitudes and adherence in asthma. Adherence rates in pharmacy records were highest for the patients accepting treatment. It is possible that the registered nonadherence could be (partially) explained by this nonacceptance of both the illness and its treatment.

Then, George et $\mathrm{al}^{15}$ showed that adherent patients had a greater understanding about their illness and had options for managing the illness. The interviewed COMIC patients showed that they had little knowledge on COPD and the way in which they can manage the disease by themselves. There was a lack of knowledge on which medication does what, and when it should be used. Also, external factors, like genetic predisposition and pollution, were frequently mentioned as causes of their disease. Although smoking was mentioned most often, almost none of the patients acknowledged smoking as the real cause of their COPD. Jessop et al $^{16}$ showed that asthma patients who believed that their asthma had been caused by external factors were less likely to adhere. Perhaps this is the case in COPD patients as well.

Furthermore, depression is also a known factor in nonadherence to medication. ${ }^{17}$ Turan et al ${ }^{18}$ found that the presence of depressive symptoms led to decreased adherence in patients with COPD.

Half of our nonadherent patients also reported depressed mood, which is in line with the review of Mikkelsen et al ${ }^{19}$ who reported a prevalence of depression up to $50 \%$ in COPD patients.

Zooming in on COPD patients with underuse and overuse, the findings of the previously published COMIC data showed that underusers have a better lung function, which might lead patients to use less medication, since they might experience fewer respiratory symptoms..$^{5}$ This is in line with the finding in the interviews in which underusers claimed using less medication because they feel well. Instead, overusers showed a real medication "dependency" which fits with the worse lung function that was previously observed in overusers. ${ }^{5}$ This worse lung function, higher dependency, and increased anxiety of dyspnea or experiencing symptoms might trigger overconsumption and could also partly be an explanation for discarding devices too early. Also, the construction of the device and the (lack of an) empty signal might lead to a premature discard. LaForce et $\mathrm{al}^{20}$ for example, showed that a dose counter relieves anxiety about running out of medication. The lack of a dose counter could have had the opposite effect in underusers. Underusers reported lower medication dependency and used their MDI until it stopped, which is using the inhaler too long.

\section{Limitations and strengths}

A strong point of this study is the qualitative design with in-depth interviews using the theoretical model for selfregulation and the fact that the authors were blinded for under- or overuse during the interview and coding process.

Saturation of topics was reached with the twenty conducted interviews. Using a top-down analysis, followed by a bottom-up approach ensured an optimal extraction of results, describing issues related to inhaled medication use in COPD patients.

A weakness in this study is the omission of data on patients with optimal use, which would represent an extra comparison group to validate the conclusions. Also, the interview data and pharmacy data were not collected in the same research period. Although this is a weakness, given the stability of medication intake in chronic disease this limitation should not be overestimated. The interview questions did not solely focus on ICS use as patients were asked to describe which medication they used and for what reason. The results showed that many patients had little knowledge of their medication. Focusing solely on ICS would have ignored the overall lack of knowledge COPD patients have on their treatment.

Another limitation could be that the number of used inhalers and the complexity of the medication regimen were not specifically addressed, as they can influence adherence. The level of patient education was also not measured. But because the COMIC cohort study is a single-center study, we assume that with regard to the level of patient education we have included a rather homogeneous group of patients. Detection of differences between under- and overusers with qualitative designs and relatively small sample sizes is difficult, but it gives indications of underlying cognitive and behavioral causes which could inspire future research on differentiating under- and overuse for inhaled medication in COPD with experimental designs to shed light on causal mechanisms.

\section{Conclusion}

Nonadherence in COPD is a multifactorial problem encompassing behavioral issues possibly caused by perceptions and knowledge of patients. Underusers and overusers showed a different pattern in perceptions and beliefs on inhaled medication.

\section{Practical implications}

When under- or overuse is detected, for example in a pharmacy, it is important to investigate the underlying reasons. 
Is the under- or overuse related to practical issues regarding knowledge on the inhaled medication or device or is the adherence influenced by beliefs and/or anxiety concerning COPD or medication? These issues need to be addressed when we want to improve therapy adherence.

\section{Acknowledgment}

We wish to thank the patients who took part in this study. We also want to thank Jeroen Hilgerink and Maurizio Dessenes for their contribution in conducting and transcribing the interviews. The results of the current study were partly presented as a poster at the European Respiratory Society Annual Congress 2017, 9-13 September 2017. The poster's abstract was published in European Respiratory Journal 2017;50:PA3944; DOI: 10.1183/1393003.congress-2017. PA3944.

\section{Disclosure}

The authors confirm all patient/personal identifiers have been removed or disguised so the patient/person(s) described are not identifiable and cannot be identified through the details of the story. The authors report no conflicts of interest in this work.

\section{References}

1. Vestbo J, Anderson JA, Calverley PM, et al. Adherence to inhaled therapy, mortality and hospital admission in COPD. Thorax. 2009; 64(11):939-943.

2. Choo PW, Rand CS, Inui TS, et al. Validation of patient reports, automated pharmacy records, and pill counts with electronic monitoring of adherence to antihypertensive therapy. Med Care. 1999;37(9): 846-857.

3. Bourbeau J, Bartlett SJ. Patient adherence in COPD. Thorax. 2008; 63(9):831-838

4. Restrepo RD, Alvarez MT, Wittnebel LD, et al. Medication adherence issues in patients treated for COPD. Int J Chron Obstruct Pulmon Dis. 2008;3(3):371-384.

5. Koehorst-ter Huurne K, Movig K, VanderValk P, van der Palen J, Brusse-Keizer M. Differences in adherence to common inhaled medications in COPD. COPD. 2015;12(6):643-648.
6. Koehorst-ter Huurne K, Movig K, VanderValk P, van der Palen J, Brusse-Keizer M. The influence of type of inhalation device on adherence of COPD patients to inhaled medication. Expert Opin Drug Deliv. 2015;13(4):469-475.

7. Koehorst-ter Huurne K, Kort S, van der Palen J, et al. Quality of life and adherence to inhaled corticosteroids and tiotropium in COPD are related. Int J Chron Obstruct Pulmon Dis. 2016;11:1679-1688.

8. Leventhal H, Diefenbach M, Leventhal EA. Illness cognition: using common sense to understand treatment adherence and affect cognition interactions. Cognit Ther Res. 1992;16(2):143-163.

9. Horne R, Weinman J. Patients' beliefs about prescribed medicines and their role in adherence to treatment in chronic physical illness. J Psychosom Res. 1999;47(6):555-567.

10. Llewellyn C, Miners A, Lee C, Harrington C, Weinman J. The illness perceptions and treatment beliefs of individuals with severe Haemophilia and their role in adherence to home treatment. Psychol Health. 2016;18(2):185-200.

11. Horne R, Weinman J. Self-regulation and self-management in asthma: exploring the role of illness perceptions and treatment beliefs in explaining non-adherence to preventer medication. Psychol Health. 2002;17(1):17-32.

12. Brusse-Keizer M, Zuur-Telgen M, van der Palen J, et al. Adrenomedullin optimises mortality prediction in COPD patients. Respir Med. 2015;109(6):734-742.

13. Brod M, Tesler LE, Christensen TL. Qualitative research and content validity: developing best practices based on science and experience. Qual Life Res. 2009;18(9):1263-1278.

14. Menckeberg TT, Bouvy ML, Bracke M, et al. Beliefs about medicines predict refill adherence to inhaled corticosteroids. J Psychosom Res. 2008;64(1):47-54.

15. George J, Kong DC, Thoman R, Stewart K. Factors associated with medication nonadherence in patients with COPD. Chest. 2005;128(5): 3198-3204.

16. Jessop DC, Rutter DR. Adherence to asthma medication: the role of illness representations. Psychol Health. 2003;18(5):595-612.

17. DiMatteo MR, Lepper HS, Croghan TW. Depression is a risk factor for noncompliance with medical treatment: meta-analysis of the effects of anxiety and depression on patient adherence. Arch Intern Med. 2000; 160(14):2101-2107.

18. Turan $\mathrm{O}$, Yemez $\mathrm{B}$, Itil $\mathrm{O}$. The effects of anxiety and depression symptoms on treatment adherence in COPD patients. Prim Health Care Res Dev. 2014;15(3):244-251.

19. Mikkelsen RL, Middelboe T, Pisinger C, Stage KB. Anxiety and depression in patients with chronic obstructive pulmonary disease (COPD). A review. Nord J Psychiatry. 2004;58(1):65-70.

20. LaForce C, Weinstein C, Nathan RA, Weinstein SF, Staudinger H, Meltzer EO. Patient satisfaction with a pressurized metered-dose inhaler with an integrated dose counter containing a fixed-dose mometasone furoate/formoterol combination. J Asthma. 2011;48(6):625-631.
Patient Preference and Adherence

\section{Publish your work in this journal}

Patient Preference and Adherence is an international, peer-reviewed, open access journal that focuses on the growing importance of patient preference and adherence throughout the therapeutic continuum. Patient satisfaction, acceptability, quality of life, compliance, persistence and their role in developing new therapeutic modalities and compounds to optimize

\section{Dovepress}

clinical outcomes for existing disease states are major areas of interest for the journal. This journal has been accepted for indexing on PubMed Central. The manuscript management system is completely online and includes a very quick and fair peer-review system, which is all easy to use. Visit http://www. dovepress.com/testimonials.php to read real quotes from published authors. 